\title{
Storage Conditions of Insulin in Domestic Refrigerators and When Carried by Patients: Often Outside Recommended Temperature Range
}

\author{
Katarina Braune, MD, Laura A. Kraemer, $\mathrm{MSc}^{2}$ Jeremias Weinstein, $\mathrm{BSc}^{2}$ \\ Amin Zayani, $\mathrm{BSc}^{2}$ and Lutz Heinemann, $\mathrm{PhD}^{3}$
}

\begin{abstract}
Objective: Not much is known about how people with diabetes store their insulin. Objective of our evaluation was to analyze at which temperature insulin is stored in domestic refrigerators and when opened/carried as a spare, and if these temperatures meet the manufacturers' recommendations.

Methods: People with diabetes $(n=338 ; 46 \%$ US, $41 \%$ EU) put Bluetooth-enabled temperature sensors (MedAngel ONE, Netherlands) next to the insulin into their refrigerator or diabetes bag. Measurement results were transferred to an app and stored in a protected online database.

Results: Temperature logs from 400 sensors were analyzed (230 for refrigerated, 170 for carried insulin). Deviations outside the recommended range were found in $315(78.8 \%)$ logs (230 [100\%] refrigerated, 85 [50\%] carried). For refrigerated insulin, temperature recorded was out of range $11.3 \%$ of the time, on average $2 \mathrm{~h}$ $43 \mathrm{~min} /$ day with an average deviation of $3.7 \mathrm{~K}$. For carried insulin, temperatures were out of range $0.5 \%$ of the time $(8 \mathrm{~min} /$ day $)$ with an average deviation of $1.1 \mathrm{~K}$. Seventeen percent of sensors measured temperatures $<0^{\circ} \mathrm{C}$ (57 of sensors for refrigerated, 9 for carried insulin).

Conclusions: Storage conditions of insulin are known to have an impact on its blood glucose-lowering effect. This is the first study investigating temperature conditions of insulin storage in industrialized countries. In a clinically relevant percentage of storage time, insulin was exposed to temperatures outside the recommended range, especially when refrigerated. Thus, domestic refrigerators may pose an underestimated risk for insulin quality.
\end{abstract}

Keywords: Diabetes, Insulin, Pharmacy, Cold supply chain, Temperature.

\section{Introduction}

A FTER INSULIN IS manufactured and transferred to pharmacies in a cold supply chain, patients with insulindependent diabetes are supposed to store their medication adequately under home conditions. Usually, insulin is stored in domestic refrigerators until first use and then carried as an opened pen or vial. So far, not much is known about how insulin is handled and stored once it leaves the controlled environment of the pharmacy. Given that patients store insulin at home before use, improper storage might have an impact on its potency at the point of use.
According to good distribution practice guidelines, storage conditions including temperature during storage and transit should be continuously monitored until the end of the cold supply chain to assure the quality of the drug. ${ }^{1-3}$ After manufacturers' and the Food and Drug Administration's (FDA) recommendations, insulin should ideally be stored in the refrigerator within a range of $+2^{\circ} \mathrm{C} / 36^{\circ} \mathrm{F}$ and $+8^{\circ} \mathrm{C} / 46^{\circ} \mathrm{F}$ for long-term storage until expiration date. Once taken out of the refrigerator, when opened or carried as a spare, it can be stored within $+2^{\circ} \mathrm{C} / 36^{\circ} \mathrm{F}$ and $+25^{\circ} \mathrm{C} / 77^{\circ} \mathrm{F}$ or $+30^{\circ} \mathrm{C} / 86^{\circ} \mathrm{F}$, but should then be used within 4 to 6 weeks, depending on the product. $^{4-7}$

\footnotetext{
${ }^{1}$ Department of Paediatric Endocrinology and Diabetes, Charité-Universitätsmedizin Berlin, Berlin, Germany.

${ }^{2}$ MedAngel BV, Nijmegen, Netherlands.

${ }^{3}$ Science \& Co., Neuss, Germany.
} 
Previous studies on home storage of other temperature sensitive medications have demonstrated that, even when leaflet instructions are being followed, the majority of patients do not always store their medication within the recommended temperature range. This was shown for antirheumatic biologic drugs, where the recommended temperature range of $2^{\circ} \mathrm{C}$ to $8^{\circ} \mathrm{C}$ was only maintained for $54.8 \%$ of storage time and only one in eight tumor necrosis factor antibodies was stored correctly in the refrigerator at home. ${ }^{8,9}$

Another study evaluated the suitability of domestic refrigerators for vaccine storage and found significant temperature disparities between different cooling zones within the same refrigerator. While some areas were shown to be warmer than recommended for medication storage, others were prone to freezing. "Dorm style" or "mini refrigerators" as they are frequently present in students' homes or hotel rooms were shown to be unable to maintain temperatures between $+2^{\circ} \mathrm{C}$ and $+8^{\circ} \mathrm{C}$ over time and were therefore not recommended for storage of temperature sensitive drugs at all. ${ }^{10}$

Objective of our investigation was to analyze storage temperatures of insulin both kept in refrigerators and carried by patients, and to evaluate how often storage conditions do not meet the manufacturers' recommendations regarding the temperature optimum.

\section{Methods}

\section{Collection of temperature data}

Patients put Bluetooth-enabled temperature sensors (MedAngel ONE, Netherlands) next to their insulin while storing them in their domestic refrigerators or in their bag next to insulin that is opened or carried as a spare. The temperature sensor used provides a measurement range from $-25^{\circ} \mathrm{C}$ to $+60^{\circ} \mathrm{C}$ with a measurement accuracy of $\pm 0.5^{\circ} \mathrm{C}$. Temperature was measured every $3 \mathrm{~min}$ (up to 480 times/day). On a mobile application connected to the sensor, the patient indicated the type of monitored drug and storage mode (refrigerated or carried).

Measurement results were stored on the sensor's internal memory and automatically sent to the app (Fig. 1). Whenever the measured temperature exceeded the range recommended by the manufacturer, the patient was notified by an alarm.
Data were transmitted online and stored in a protected database provided by the manufacturer of the sensor. Patients have purchased the sensors on their own initiative and expense. All participants have given their consent that their data are being analyzed for scientific purposes.

\section{Data analysis}

Data were analyzed using a statistical software package (Desktop Professional v 10.5; Tableau Software, Inc.). Since patients indicated the type of drug that they monitored only temperature $\operatorname{logs}$ for insulin were filtered and analyzed. In total, 400 sensors were identified and subsequently divided into two groups: insulin that was stored in a refrigerator and insulin that was carried. The primary end point of our evaluation was the proportion of time that insulin was stored outside the recommended temperature range. Out-of-range storage was defined by temperature excursions below $+2{ }^{\circ} \mathrm{C} / 36^{\circ} \mathrm{F}$ in both groups and above $+8^{\circ} \mathrm{C} / 46^{\circ} \mathrm{F}$ for refrigerated and $+30^{\circ} \mathrm{C} / 86^{\circ} \mathrm{F}$ for carried insulin, respectively.

\section{Results}

A total number of 400 sensors were used by 338 patients (46\% located in the United States, $41 \%$ in the European Union) and kept next to their insulin. Temperature data were collected from November 2016 to February 2018. The total recorded storage time was 19,660 days with an average recorded time of 49 days per temperature sensor, ranging from 1 to 435 days. Deviations from the recommended temperature range were found in $315(78.8 \%)$ out of all $400 \operatorname{logs}$ (Table 1, Fig. 2).

Two hundred thirty sensors recorded temperature data for refrigerated insulin with a total storage time of 9606 days. Deviations from the recommended range of $2^{\circ} \mathrm{C}$ to $8^{\circ} \mathrm{C}$ were found in $100 \%$ of the logs with temperatures out of range for $11.3 \%$ (95\% confidence interval [CI]: $10.1 \%-13.1 \%$ ) of the total storage time, which corresponds to $2 \mathrm{~h} 43 \mathrm{~min} /$ day or 3 days/month (Fig. 2A, B). The average temperature deviation was $3.7 \mathrm{~K}(\mathrm{SD} 5.0 \mathrm{~K})$. Temperatures $<0^{\circ} \mathrm{C}$ were recorded by $24.8 \%$ of the sensors in $0.4 \%$ of the total storage time, which corresponds to $3 \mathrm{~h} / \mathrm{month}$ (Fig. 3 ). The individual data sets revealed patterns of recurrent temperature fluctuations in the
FIG. 1. Temperature monitoring with a Bluetooth-enabled sensor. Patients put Bluetooth-enabled temperature loggers (MedAngel ONE, Netherlands) next to their insulin in the refrigerator or in their bag next to insulin that is opened or carried as a spare. Temperature measurements were sent to a mobile application on a smartphone, transmitted online, and stored in a protected database.

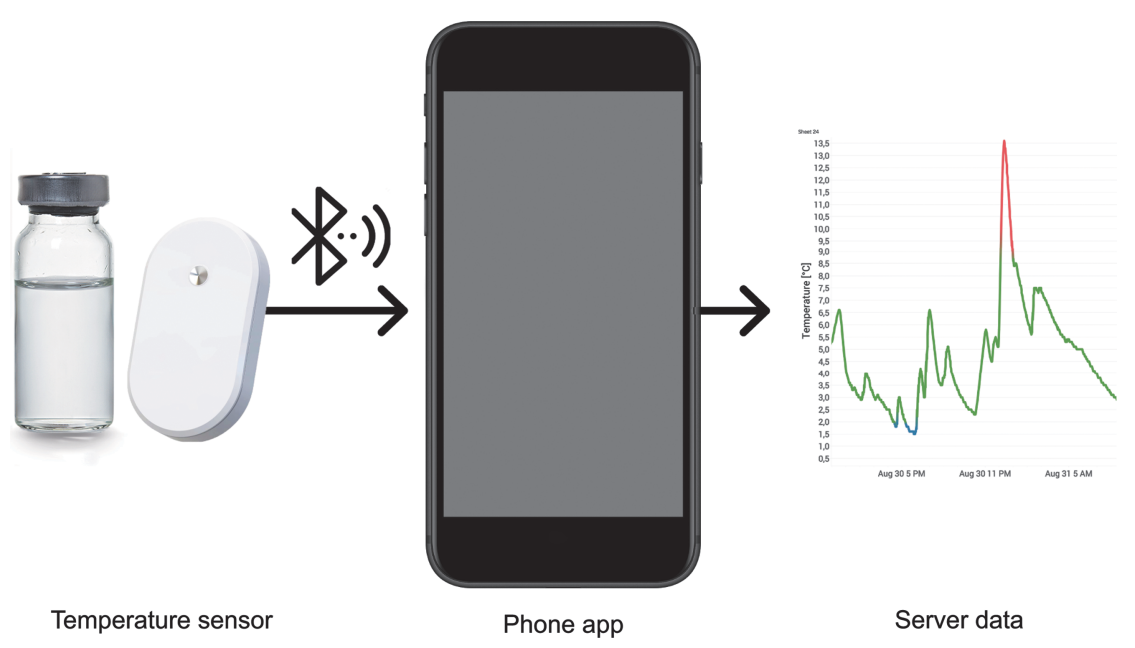


Table 1. Temperature Recordings by Means of a Temperature Sensor located Nearby THE INSULIN STORED IN A REFRIGERATOR OR IN A BAG

\begin{tabular}{lcc}
\hline & Refrigerated insulin & Carried insulin \\
\hline Temperature sensors, $n$ & 230 & 170 \\
Safe temperature range, ${ }^{\circ} \mathrm{C}$ & $2-8$ & $2-30$ \\
Total measurement time, days & 9606 & 10,054 \\
Measurement time per sensor, mean, days & 42 & 60 \\
Time in range, mean, $\%$ & 88.7 & 99.5 \\
Total temperature deviation, mean (SD), K & $3.7(5.0)$ & $1.1(1.2)$ \\
Time above upper limit, $\%$ & 7.73 & 0.18 \\
Temperature deviation above upper limit, mean (SD), K & $4.9(5.6)$ & $1.7(1.7)$ \\
Time below lower limit, \% & 3.58 & 0.36 \\
Temperature deviation below lower limit, mean (SD), K & $1.0(1.0)$ & $0.8(0.8)$ \\
Time below $0^{\circ} \mathrm{C}, \%$ & 0.41 & 0.02 \\
Temperature deviation below $0^{\circ} \mathrm{C}$, mean $(\mathrm{SD}), \mathrm{K}$ & $1.0(1.2)$ & $1.1(1.5)$
\end{tabular}

$\mathrm{SD}$, standard deviation.

refrigerator, partly from in-range temperatures to out-ofrange temperatures (Fig. 4).

With a total storage time of 10,054 days, 170 sensors recorded temperature data for insulin that had been opened or was carried as a spare (Fig. 2C, D). Deviations from the recommended $2^{\circ} \mathrm{C}$ to $30^{\circ} \mathrm{C}$ were found in $85(50 \%)$ of these logs. Temperatures out of range were measured $0.5 \%$ of the time (95\% CI: $0.5 \%-0.6 \%$ ), which is equivalent to $8 \mathrm{~min} /$ day or $4 \mathrm{~h}$ a month, with an average temperature deviation of $1.1 \mathrm{~K}$ (SD 1.2 K) (Fig. 2).
A
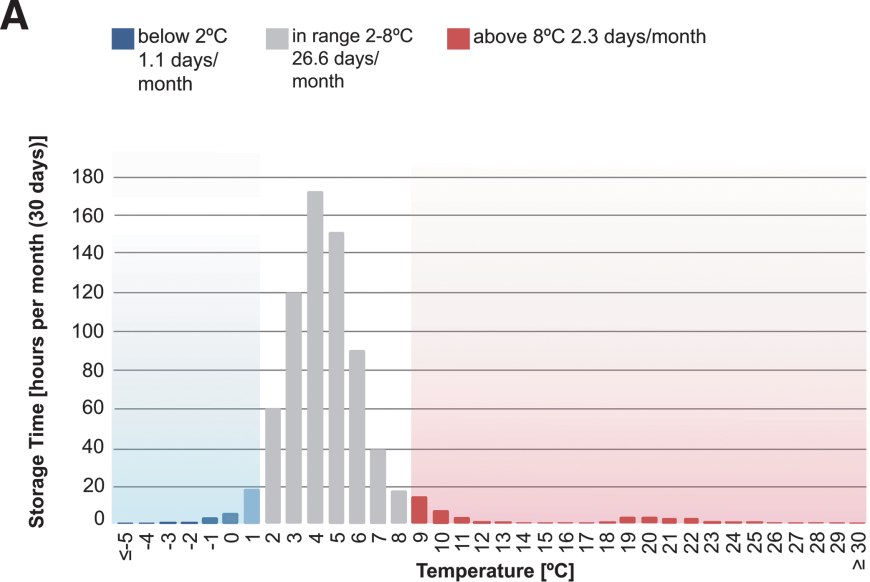

\section{C}
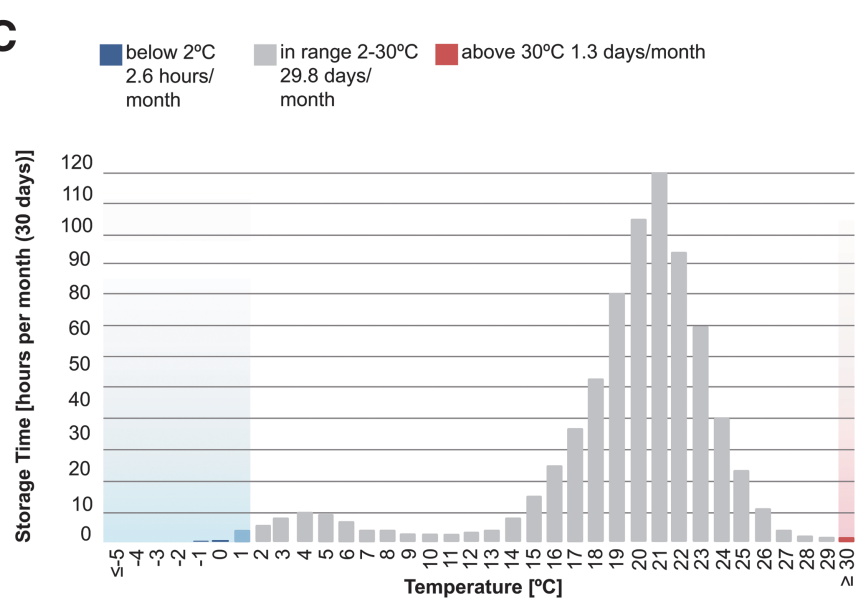

B

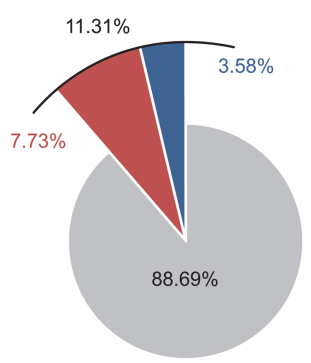

$>8^{\circ} \mathrm{C}$

Time in range

D

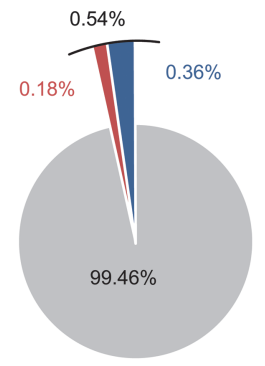

$>30^{\circ} \mathrm{C}$

$<2^{\circ} \mathrm{C}$

Time in range

FIG. 2. Distribution of storage time in hours/month per temperature $\left({ }^{\circ} \mathrm{C}\right)$. The proportion of total storage time in range $\left(2^{\circ} \mathrm{C}-8^{\circ} \mathrm{C}\right.$ for refrigerated and $2^{\circ} \mathrm{C}-30^{\circ} \mathrm{C}$ for carried insulin) is indicated in gray, the proportion below the recommended range in blue, and above the recommended range in red. $(\mathbf{A}, \mathbf{B})$ Refrigerated insulin. $(\mathbf{C}, \mathbf{D})$ Insulin opened or carried as a spare. 
25.8 hours $/$ month below $2^{\circ} \mathrm{C}\left(3.1\right.$ hours/month below $\left.0^{\circ} \mathrm{C}\right)$

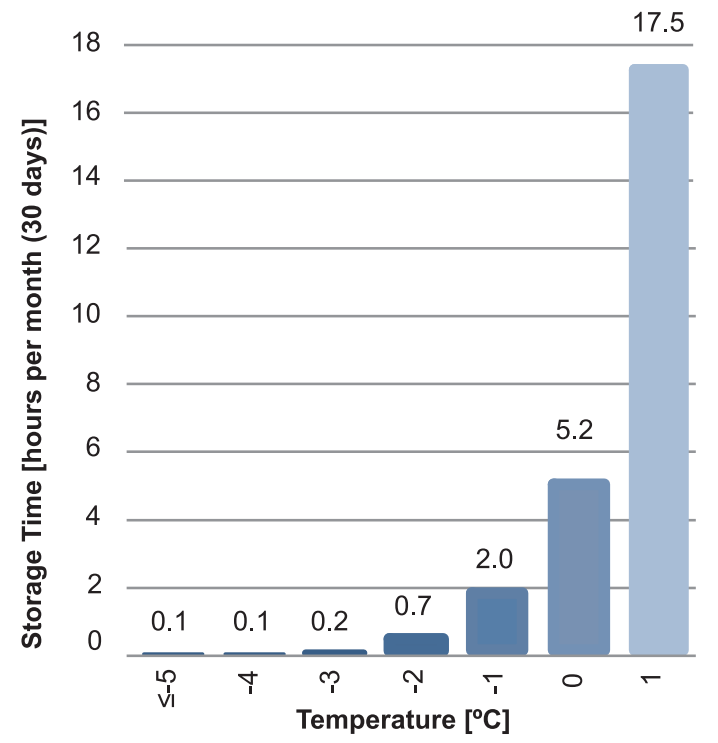

FIG. 3. Distribution of storage time of insulin in refrigerators in hours/month per temperature $\left({ }^{\circ} \mathrm{C}\right)$ for temperatures below $2^{\circ} \mathrm{C}$. Temperatures $<0^{\circ} \mathrm{C}$ were recorded by $24.8 \%$ of the sensors for $0.4 \%$ of the total storage time, which corresponds to $3 \mathrm{~h} / \mathrm{month}$.

\section{Discussion}

This evaluation shows that in daily life of patients with diabetes insulin was exposed to temperatures outside the recommended range to an extent that can be clinically relevant. Especially, refrigerated insulin was exposed to temperatures below the recommended range, even below freezing point. These results are in line with other publications on storage conditions on domestic refrigerators for other types of temperature sensitive medication. ${ }^{8,9,11}$ However, to our knowledge, this is the first study investigating temperature conditions of insulin storage under home conditions of patients with diabetes in industrialized countries.

Optimal storage conditions of temperature sensitive drugs like insulin are crucial for their quality, that is, biological activity after subcutaneous administration. For people with diabetes who take insulin several times a day via injections or continuously administer insulin with a pump, precise dosing is essential to achieve optimal therapeutic outcomes. Even gradual loss of potency might introduce an unnecessary variability in insulin dosing and the insulin induced metabolic effects. It is well known that the blood glucose-lowering effect of insulin is reduced when it was exposed to temperatures well outside the recommended range for longer periods of time. ${ }^{12-14}$ However, little information is publicly available about the impact on insulin potency of shorter or repeated temperature deviations below or above the recommended storage conditions.

While labels state storage temperature ranges and recommend to not use insulin after the formulation had been frozen, there are no further indications on how exposure to higher or lower temperatures for a certain time impacts insulin potency. The number of recent publications about the impact of temperature deviations on insulin potency is scarce. Recently, a study indicated that insulin concentration in vials purchased randomly from pharmacies in the United States
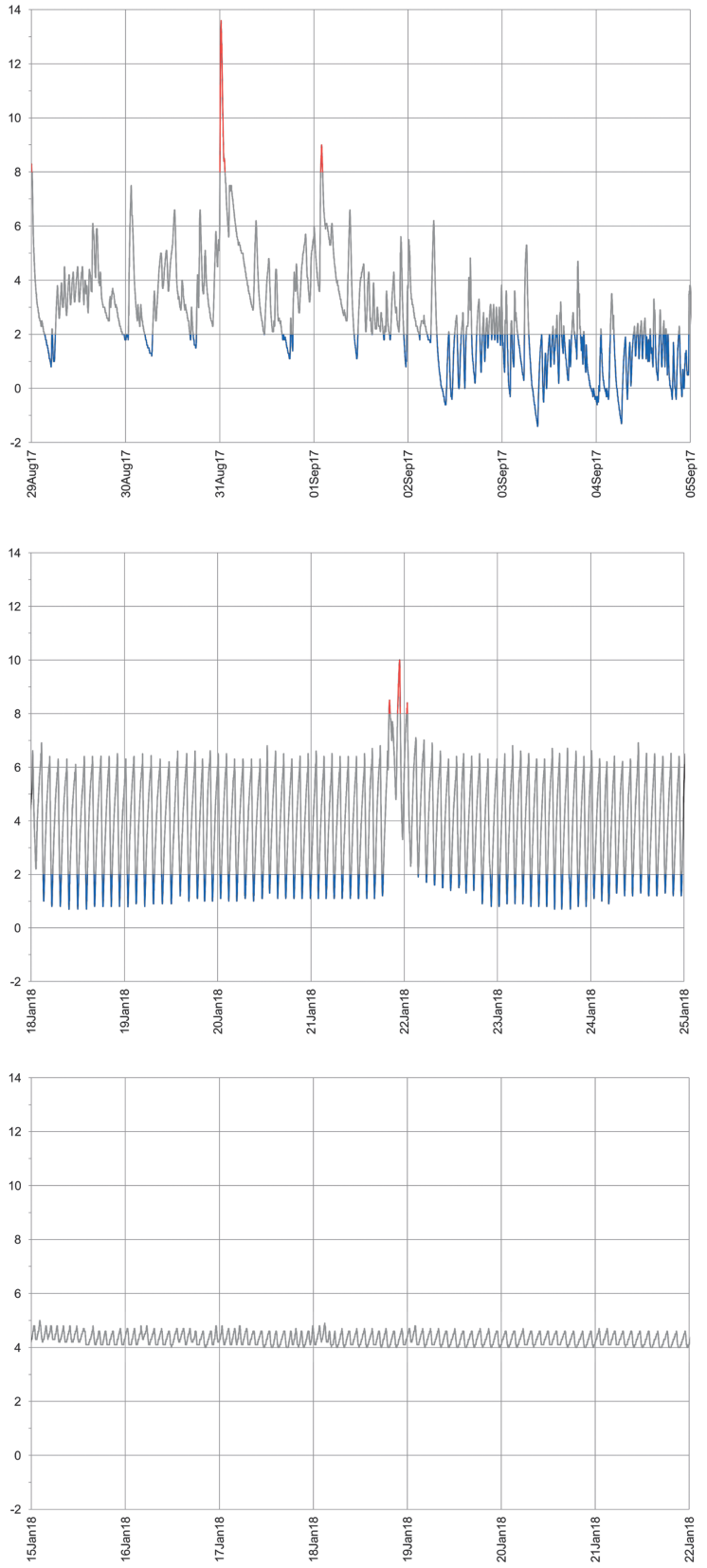

FIG. 4. Storage patterns of three examples of individual temperature logs. Temperature $\left({ }^{\circ} \mathrm{C}\right)$ over time recorded by a temperature logger located in three different refrigerators.

Midwest had insulin concentration well below the expected level of $95 \mathrm{U} / \mathrm{mL}$ required by the FDA. ${ }^{15,16}$ These findings have been challenged by others. ${ }^{17,18}$ Although there are documented cases of insulin that was rendered ineffective after exposure to heat and sunlight, ${ }^{12}$ other research states that insulin formulations are to an extent resistant to temperature excursions. A possible reason for these different findings might be the method used to measure insulin potency. The FDA approved high performance liquid chromatography (HPLC) method was shown to be insensitive to structural changes induced by storage temperatures, which, however, might be of relevance for the metabolic activity. Insulin was shown to maintain its quality when assessed by 
HPLC, size exclusion chromatography, and microscopy inspection after temperature excursions to heat $\left(+45^{\circ} \mathrm{C}\right)$ and cold $\left(-10^{\circ} \mathrm{C}\right)$ during 1 to 3 days long simulated transit conditions, which occur for mail order medications. ${ }^{13}$ A study conducted in India investigated insulin quality by HPLC and in vivo tests in rabbits after sustained storage at high temperatures. They found that insulin formulations started to lose bioactivity after 2 weeks exposed to temperatures of $+32^{\circ} \mathrm{C}$ and $+37^{\circ} \mathrm{C} .{ }^{14}$ The standard method to assess insulin potency is HPLC, as recommended by the FDA. Other methods might be more sensitive toward the biological activity of peptides.

There is little publicly available data on the exact effects of storage temperature excursions on insulin potency and clinical outcomes. Some health authorities give recommendations for acceptable storage conditions in an emergency setting. The FDA, in their information for insulin storage in an emergency, acknowledges that insulin exposed to temperatures above $30^{\circ} \mathrm{C}$ could still be used if needed. Frozen insulin however, should not be used, even in an emergency. ${ }^{4}$ The East Africa Diabetes Study Group defines temperature limits of $0^{\circ} \mathrm{C}$ and $32^{\circ} \mathrm{C}$ as harmful for insulin quality in a setting where insulin and electricity are scarce. ${ }^{19}$

The mobile application used in this study sent notifications to the patient's phone when temperature deviations were detected. As the patients might have reacted accordingly to prevent storage at inappropriate conditions, the time at which insulin is stored at too low or high temperatures might be underestimated. However, alarms were only triggered when the phone was within physical proximity to the sensor.

The participants in this evaluation have purchased temperature sensors on their own initiative and expense. Therefore, it is likely that the participants of this evaluation showed previous interest in the topic of medication storage and are likely to be aware of the temperature sensitivity of insulin. To avoid such a positive bias, it would be of interest to repeat this evaluation with a variety of patient populations. Furthermore, the low percentage of temperatures out of recommended range for carried insulin might have occurred due to possible little exposure to high temperature climates in the study cohort that was mainly located in countries in moderate climate zones. This might be different for study populations located in other climates or if temperatures were logged blinded without any temperature alarms given by the app.

Awareness of patients with diabetes about correct insulin storage has been researched before, although for populations living in hot climates. A survey from 2010 conducted in the southwestern United States found high awareness about heat sensitivity of insulin. Eighty percent of the participants correctly stated they start taking measures to protect their medication from ambient temperatures of $+27.2^{\circ} \mathrm{C} /+81^{\circ} \mathrm{F}$ to $29.4^{\circ} \mathrm{C} /+85^{\circ} \mathrm{F}$ and up. $^{20}$

Deviations from the recommended temperature range, especially below $+2^{\circ} \mathrm{C}$, occurred mostly for insulin stored in a refrigerator. This suggests that domestic refrigerators are at least intermittently too cold for medication storage, with an unknown impact of repeated excursions to temperatures over the course of several weeks or months on insulin quality. These results confirm the findings of previous studies that have demonstrated inadequate storage conditions for drugs in the refrigerator at home. ${ }^{8,9,11}$ While the label recommends storage between $+2^{\circ} \mathrm{C}$ and $+8^{\circ} \mathrm{C}$, temperatures in most household refrigerators fluctuate over a wider range. A French study on food safety, showed a mean temperature fluctuation of 0.9 to $11.4 \mathrm{~K}$ in refrigerators, with an absolute minimum of $-1.6^{\circ} \mathrm{C}$ and maximum of $+12^{\circ} \mathrm{C}$, depending on the placement of a temperature logger at the top, middle or bottom shelf. ${ }^{21}$

Various factors have potential influence on temperatures in a refrigerator compartment, making it difficult to give general recommendations on medication storage in the refrigerator. Factors that might influence medication storage temperature in refrigerators include: thermostat settings, placement of medication within the refrigerator, frequency of door openings, adjacent sources of heat (e.g. dishwashers), how full the refrigerator is and how different other items are arranged within the refrigerator, and type and age of the refrigerator. ${ }^{11,21}$ An investigation of home storage of biologic drugs found that refrigerators older than 5 years pose a risk factor for inadequate storage. ${ }^{11}$ The average household replaces its refrigerator every 7.8 years in the United Kingdom and every 14 to 18 years in the United States. ${ }^{21,22}$

The composition of warm and cold zones within a refrigerator depends on the type, for example, a compact refrigerator with one door and a top freezer or a large refrigerator with two doors and a separate freezer. As a temperature analysis of household refrigerators has shown, the coldest spot varies, and might be the top shelf for one type of refrigerator and the bottom drawer for another model. ${ }^{10,21,23}$ Furthermore, many domestic refrigeration systems are prone to a temperature drift toward cold temperatures. Especially, mini refrigerators as they are often found in hotel rooms and university dormitories have shown a severe drift to below freezing point, due to the lack of adequate air circulation. ${ }^{10}$ Furthermore, thermostat settings are not a reliable indicator for the actual refrigerator temperature. ${ }^{21}$

To choose the best placement and temperature setting for their medications, patients need to know about the location of warm and cold zones and the temperature progression over time of the refrigerator model in use. In the cold supply chain, this is managed by using qualified refrigerators and temperature monitoring systems. Temperature monitoring is a requirement for all steps in the distribution chain up to the point that medications are dispensed to the patient and could prove effective in reducing storage time outside the recommended temperature range for patients as well. ${ }^{1-3}$

Even in low and middle income countries with less resources, a thermometer is considered a necessity in refrigerators that store insulin. ${ }^{19}$ The use of data loggers with continuous temperature monitoring and alarms was shown to be superior over the use of a simple thermometer or a min$\max$ thermometer in previous studies. An investigation of 120 household refrigerators in France showed no correlation between the temperatures measured using a thermometer at a given moment and using a data logger over a 7 day period. ${ }^{21}$ This is illustrated by the fluctuating temperature patterns detected by sensors in refrigerators. Also, the use of min-max thermometers, which are widely used in pharmacies, misses a number of temperature excursions, opposed to sensors with continuous monitoring. ${ }^{24-26}$

The data evaluated here were obtained from patients who were using temperature data sensors with alarms. A future investigation should compare storage conditions of insulin in domestic refrigerators before the use of such a temperature sensor and after intervention. Furthermore, more detailed information in the package leaflet for the given refrigerator 
about the different temperature zones is needed. Further investigations on the information sources publicly available, and pharmacists' and patients' awareness level on proper medication storage and patients' distress concerning insulin quality might be of interest.

\section{Conclusions}

In conclusion, insulin is stored outside the recommended temperature range for a considerable part of the time in daily practice of patients with diabetes on insulin treatment. Storage of insulin in domestic refrigerators may pose an underestimated risk for insulin quality. The extent to how temperature deviations in storage affect insulin potency and patient outcomes needs further systematic investigation.

\section{Acknowledgments}

We thank all MedAngel ONE users for their contribution to this study. This research received no specific grant from any funding agency in the public, commercial, or not-forprofit sectors. The authors received no financial funding for the research and/or publication of this article.

\section{Author Disclosure Statement}

All authors have completed the Unified Competing Interest form (available on request from the corresponding author). Dr. Katarina Braune reports grants from the Berlin Institute of Health (BIH) Junior Clinician Scientist programme and the European Union H2020-MSCA-RISE-2018 programme, fees for medical consulting from Medtronic Diabetes as a member of the Advisory Board "Impact," medical consulting fees from Roche Diabetes Care, paid talks for Dexcom, Medtronic Diabetes, and Bertelsmann Stiftung, outside the submitted work. Laura Krämer, Jeremias Weinstein, and Amin Zayani are full-time employees at MedAngel BV. The company was the recipient of the 2017 Lyfebulb-Novo Nordisk Innovation Award. MedAngel BV was awarded a prize of USD $\$ 25,000$, which was nonconditional and able to be used for any purpose, received from Novo Nordisk A/S, Denmark. The award, organized in collaboration of Lyfebulb and Novo Nordisk, aims to recognize and empower international $\mathrm{Pa}$ tient Entrepreneurs to disrupt the future of diabetes management. Lyfebulb is a business focused on bridging patient communities with industry by empowering Patient Entrepreneurs. Novo Nordisk is a global health care company focused on diabetes care and an insulin manufacturer. Prof. Dr. Lutz Heinemann has nothing to disclose.

\section{Authors' Contributions}

Literature search: K.B., L.A.K., L.H.; Designed the study: K.B., L.A.K., J.W., A.Z., L.H.; Data collection: L.A.K., A.Z., J.W.; Data analysis and interpretation: K.B., L.A.K., J.W., A.Z., L.H.; Wrote the article: K.B., L.A.K., L.H.; Read and approved the article: K.B., L.A.K., J.W., A.Z., L.H.; Guarantor of the study: K.B.

\section{References}

1. USP: Good Storage and Distribution Practices for Drug Products. Rockville, MD: United States Pharmacopeial Convention, 2016.
2. WHO Expert Committee on Specifications for Pharmaceutical Preparations. Model guidance for the storage and transport of time- and temperature-sensitive pharmaceutical products. WHO Technical Report Series, No. 961, Annex 9; Geneva, World Health Organization, 2011.

3. European Commission: Guidelines of 5 November 2013 on Good Distribution Practice of Medicinal Products for Human Use. Official Journal of the European Union. Commission guideline 2013/C343/01.

4. Information Regarding Insulin Storage and Switching Between Products in an Emergency [Internet]. Fda.gov. www.fda.gov/drugs/emergencypreparedness/ucm085213.htm (accessed September 20, 2018).

5. HUMALOG ${ }^{\circledR}$ Label, Lilly USA, LLC. www.accessdata .fda.gov/drugsatfda_docs/label/2017/020563s176lbl.pdf (accessed September 20, 2018).

6. FIASP ${ }^{\circledR}$ Label, Novo Nordisk A/S. www.accessdata .fda.gov/drugsatfda_docs/label/2018/208751s005lbl.pdf (accessed September 20, 2018).

7. LANTUS ${ }^{\circledR}$ Label, Sanofi-Aventis U.S. LLC www.accessdata .fda.gov/drugsatfda_docs/label/2015/021081s063lbl.pdf (accessed September 20, 2018).

8. Vlieland ND, Gardarsdottir H, Bouvy ML, et al.: The majority of patients do not store their biologic diseasemodifying antirheumatic drugs within the recommended temperature range. Rheumatology 2016;55:704-709.

9. de Jong M, Pierik M, Peters A, et al.: Exploring conditions for redistribution of anti-tumor necrosis factors to reduce spillage: A study on the quality of anti-tumor necrosis factor home storage. J Gastroenterol Hepatol 2018;33:426-430.

10. Chojcnacky M, Miller W, Ripple D, Strouse G: NISTIR 7656 Thermal Analysis of Refrigeration Systems Used for Vaccine Storage. U.S. Department of Commerce: National Institute of Standards and Technology, 2009.

11. Cuéllar M, Marco J, Pérez-Castelló I, Castelló Escrivá A: Calidad en la conservación de los medicamentos termolábiles en el ámbito domiciliario. [Quality of storage of thermolabile drugs in patients' homes.] Rev Cal Asist 2010;25:64-69.

12. Pryce R: Diabetic ketoacidosis caused by exposure of insulin pump to heat and sunlight. BMJ 2009;338:a2218-a2218.

13. Chandler C, Gryniewicz C, Pringle T, Cunningham F: Insulin temperature and stability under simulated transit conditions. Am J Health Syst Pharm 2008;65:953-963.

14. Vimalavathini R, Gitanjali B: Effect of temperature on the potency and pharmacological action of insulin. Indian $\mathbf{J}$ Med Res 2009;130:166-169.

15. Carter AW, Heinemann L, Klonoff DC: Quality control of insulins and biosimilar insulins: what do we know? J Diabetes Sci Technol 2016;10:811-815.

16. Carter AW, Heinemann L: Insulin concentration in vials randomly purchased in pharmacies in the United States: considerable loss in the cold supply chain. J Diabetes Sci Technol 2018;12:839-841.

17. Petersen M, Hirsch I, Skyler J, et al.: In Response to Carter and Heinemann: Insulin Concentration in Vials Randomly Purchased in Pharmacies in the United States: Considerable Loss in the Cold Supply Chain. J Diabetes Sci Technol 2018;12:890-891.

18. Carter AW, Heinemann L: In Response to Letters to the Editor From the American Diabetes Association and Eli Lilly in Regard to: Insulin Concentration in Vials Randomly Purchased in Pharmacies in the United States: Considerable Loss in the Cold Supply Chain. J Diabetes Sci Technol 2018;12:1072-1077. 
19. Bahendeka S, Kaushik R, Swai AB, et al.: EADSG Guidelines: Insulin Storage and Optimisation of Injection Technique in Diabetes Management. Diabetes Ther 2019 [Epub ahead of print]; DOI: 10.1007/s13300-019-0574-x.

20. Nassar A, Childs R, Boyle M, et al.: Diabetes in the desert: what do patients know about the heat? J Diabetes Sci Technol 2010;4:1156-1163.

21. Laguerre O, Derens E, Palagos B: Study of domestic refrigerator temperature and analysis of factors affecting temperature: a French survey. Int J Refrigeration 2002;25: 653-659.

22. Kim HC, Keoleian GA, Horie YA: Optimal household refrigerator replacement policy for life cycle energy, greenhouse gas emissions, and cost. Energy Policy 2006;34; 2310-2323.

23. James S, Evans J, James C: A review of the performance of domestic refrigerators. J Food Eng 2008;87:2-10.

24. Lloyd J, Lydon P, Ouhichi R, Zaffran M: Reducing the loss of vaccines from accidental freezing in the cold chain: the experience of continuous temperature monitoring in Tunisia. Vaccine 2015;33:902-907.

25. Kartoğlu Ü, Nelaj E, Maire D: Improving temperature monitoring in the vaccine cold chain at the periphery: an intervention study using a 30-day electronic refrigerator temperature logger (Fridge-tag ${ }^{\circledR}$ ). Vaccine 2010;28:4065-4072.

26. Worz C, Postolski J, Williams K: The utility of continuous temperature monitoring of refrigerators in a long-term care facility. Consult Pharm 2017;32:222-227.

Address correspondence to: Katarina Braune, MD

Department of Paediatric Endocrinology and Diabetes Charité-Universitätsmedizin Berlin Augustenburger Platz 1 Berlin 13353

Germany

E-mail: katarina.braune@charite.de 